\title{
Cutaneous Melanoma pN1a TNM Finding v7
}

National Cancer Institute

\section{Source}

National Cancer Institute. Cutaneous Melanoma pN1a TNM Finding v7. NCI Thesaurus. Code $C 88388$.

Cutaneous melanoma with micrometastasis in one regional lymph node.

Micrometastases are diagnosed after sentinel lymph node biopsy and completion of lymphadenectomy (if performed). (from AJCC 7th Ed.) 